\title{
Investigation of the relative bottomside/topside contribution to the total electron content estimates
}

\author{
Anna Belehaki and Ioanna Tsagouri \\ Institute for Space Applications and Remote Sensing, National Observatory of Athens, Palaia Penteli, Greece
}

\begin{abstract}
High-resolution vertical electron density true height profiles from Athens Digisonde are used to calculate the electron content up to the peak of the $F_{2}$ layer (bottomside electron content) and also the topside electron content up to $1000 \mathrm{~km}$, using the Huang-Reinisch method, to investigate the relative behavior of these two parameters during storm events. It was shown that the topside electron content represents roughly the $2 / 3$ of the total electron content of the ionosphere and it is strongly affected by the geomagnetic activity, much more than the bottomside electron content. During daylight hours the values of the topside electron content exhibit intense fluctuations, while they become smoother in nature during events of night-time $F_{2}$ layer uplifting caused by the auroral activity. All these facts demonstrate that the Huang-Reinisch method provides a realistic tool for monitoring the variations of the ionospheric ionisation at a given location and it could be used in the frames of a world wide effort for the development of realistic models to accurately predict the electron content and to support effectively earth-space communications including navigation systems.
\end{abstract}

Key words bottomside electron content - topside electron content - ionospheric storm effects

\section{Introduction}

So far, dual frequency transmissions from Global Positioning Systems (GPS) have been used to derive the Total Electron Content (TEC) of the ionosphere and to study aspects of the thermospheric/ionospheric storm event. As former studies have shown (e.g., Titheridge and Buonsanto, 1980; Jakowski et al., 1990, 1999; Ho et al., 1996), TEC data can help to understand

Mailing address: Dr. Anna Belehaki, Institute for Space Applications and Remote Sensing, National Observatory of Athens, Metaxa and Vas. Pavlou str., Palaia Penteli 15236, Greece; e-mail: belehaki@ space.noa.gr the complex behaviour of competing interactive processes in the course of ionospheric storms. A useful add-in to the study of ionospheric storms in the light of TEC variations would be the study of the variation of electron content in various ionospheric layers, separately.

The operation of a Lowell DPS4 in Athens $\left(38^{\circ} \mathrm{N}, 23.5^{\circ} \mathrm{E}\right)$ since September 2000 , gave us the possibility to obtain a large amount of high quality ionospheric data with 15 min time resolution. Among them, three parameters were selected to be used in this study to determine the structure of the $F_{2}$ layer: the critical frequency $f_{0} F_{2}$; the true height of the $F_{2}$ peak, $h_{m} F_{2}$; and finally the lower boundary of the $F_{2}$ layer height, $h_{m} F_{2}$-B0, where $\mathrm{B} 0$ is the IRI thickness parameter. Three more parameters were derived to determine the electron content in various ionospheric layers, that is the vertical total electron content from ionograms, ITEC, the bottomside electron 
content BTEC and the topside electron content TTEC. The method of derivation of these three parameters will be presented in detail in the following section.

The aim of this contribution is to study the behaviour of the topside electron content, derived from ground ionograms, under various levels of geomagnetic activity and to investigate the contribution of bottomside versus the topside electron content to the total electron content estimates.

\section{Ionograms processing and electron content calculation}

Athens Digisonde Portable Sounder auto scales the ionograms and provides radio channel information in real time. Data and ionograms are available in real time on the World Wide Web (http://www.iono.noa.gr). Polarisation switching and multibeam forming are the important characteristics for successful auto scale under disturbed and undisturbed conditions. Auto scaling algorithms find the leading edge of the $\mathrm{O}$ echo traces, i.e. $h^{\prime}(f)$, and determine the standard ionosphere characteristics. ARTIST software provides reliable vertical electron density profiles, using the Chebyshev polynomial fitting technique (Reinisch and Huang, 1983; Huang and Reinisch, 1996).

Regarding the determination of the topside vertical electron density profile, the new technique of Huang and Reinisch (2001) is applied. This method uses information from ground based ionosonde measurements. According to this technique, the vertical total electron content from ground-based ionograms (ITEC) is given by

ITEC $=\int_{0}^{\infty} N(h) d h=\int_{0}^{h_{m} F_{2}} N_{B}(h) d h+\int_{h_{m} F_{2}}^{\infty} N_{T}(h) d h$

where, $N$ is the vertical electron density profile, $N_{B}$ is the vertical electron density profile up to $F_{2}$ layer peak (bottom profile) calculated using the inversion program proposed by Huang and Reinisch (1996) and $N_{T}$ is vertical electron density profile above the $F_{2}$ layer peak (topside profile).

$N_{B}(h)$ is calculated from the measured $h^{\prime}(f)$ traces in the ionogram (information directly provided from the ionograms). $N_{T}(h)$ is approximated by an a-Chapman function with a constant scale height $H_{T}$ that is derived from the profile shape at the $F_{2}$ peak, where

and

$$
N_{T}=N_{m} F_{2} \cdot \exp \left[\frac{1}{2}\left(1-z-e^{-z}\right)\right]
$$

$$
z=\frac{h-h_{m} F_{2}}{H_{T}} .
$$

The characteristic parameters that define the shape of the bottomside electron density profile determine also the value of ITEC parameter.

A preliminary ITEC validation was performed by Huang and Reinisch (2001) by comparing ITEC with TEC values derived from incoherent scatter radar and geostationary satellite beacon measurements at middle latitudes, and with TOPEX measurements at the equator. They concluded that since ITEC is obtained from vertical measurements it does not suffer from the uncertainties associated with converting slant TEC to vertical TEC.

All ionograms used in this study to derive the ITEC values and also various parameters which characterize the state of the $F_{2}$ layer, were further edited to ensure data integrity and minimize uncertainties especially during periods of high disturbances.

\section{Validation of ITEC values used in this analysis}

To validate of ITEC values extracted according to the Huang and Reinisch (2001) method using parameters from the vertical ground ionograms taken with Athens Digisonde, we compared the 15 min ITEC estimates with the TEC values measured from the GPS network. The GPS-TEC estimates were provided by Luigi Ciraolo of the Istituto di Ricerca sulle Onde Elettromagnetiche in Florence, Italy, using 

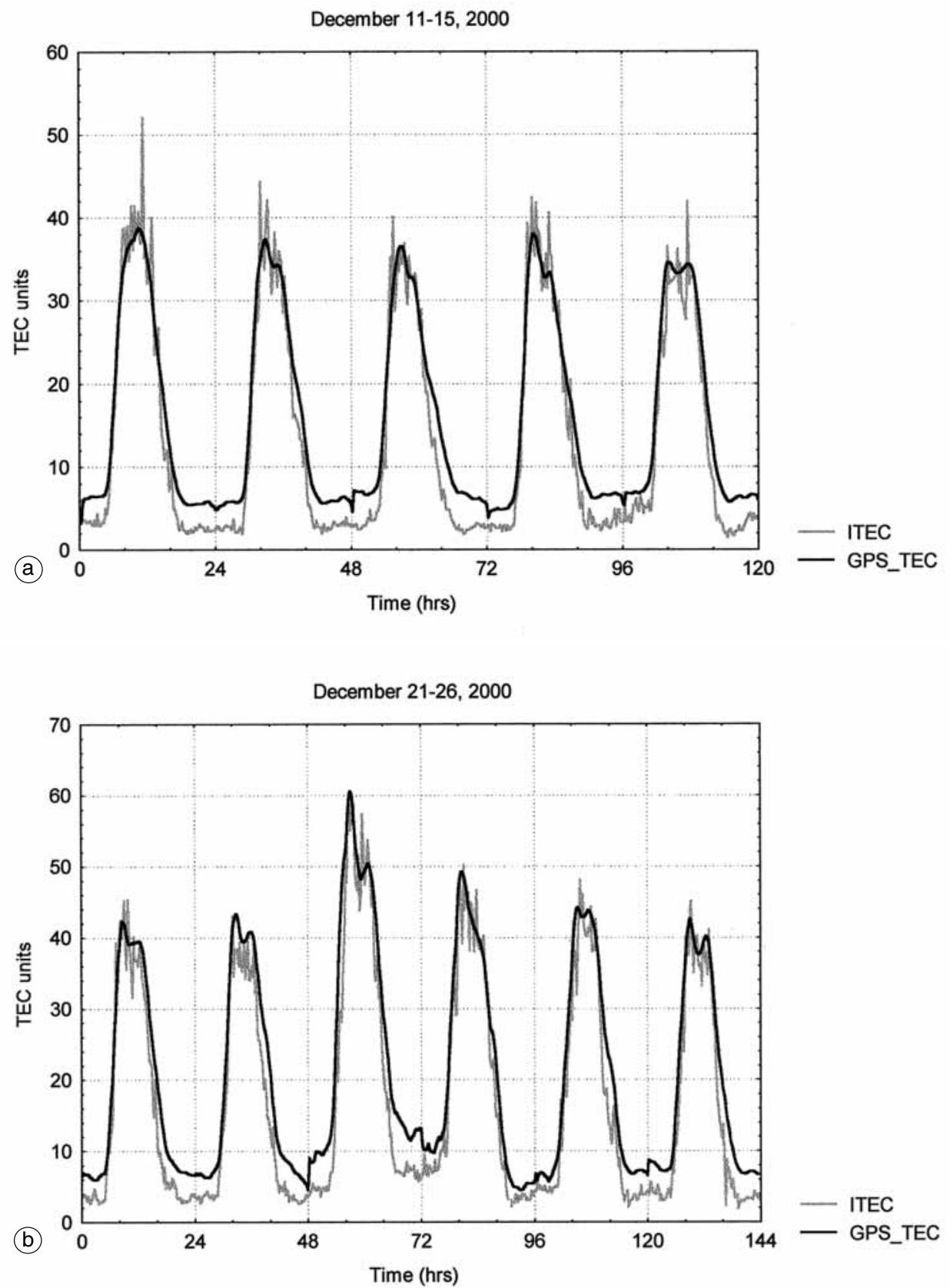

Fig. 1a,b. The GPS-TEC and the ITEC estimates for two time periods: a) a quiet one, from 11 to 15 December 2000 , consisting of five consecutive days of geomagnetic and ionospheric conditions over Athens; $b$ ) a disturbed period 21-26 December 2000, during which a geomagnetic storm caused positive storm effects in the ionosphere over Athens. 
slanting TEC from Matera and Ankara GPS receivers. An assumption of a mapping function and an approximation of the vertical TEC by a linear development in latitude and longitude are involved to estimate GPS-TEC over Athens (Ciraolo and Spalla, 1997). The comparison between the two data sets was concentrated on two time periods, a quiet one, from 11 to 15 December 2000, consisting of five consecutive days of quiet geomagnetic and ionospheric conditions over Athens, and a disturbed period during which a geomagnetic storm caused positive storm effects in the ionosphere over Athens. The time plots of the two data sets are presented in fig. 1a,b respectively for the quiet and the disturbed period. The main points that have to be discussed from the comparison between the two data sets are:

a) The two parameters are generally in good agreement during either quiet or disturbed geomagnetic conditions.

b) Systematic bias during night-hours is observed. The GPS-TEC values are higher by 1-2 TEC units in comparison to ITEC estimates. This bias might be caused by errors involved in the procedure followed to derive the GPS-TEC (L. Ciraolo, personal communication), that are uncertainties in mapping function and in the vertical TEC model, possible influence of multipath signal propagation and possible presence of gradients. Also possible cause for the observed bias might be the different estimation of plasmaspheric fluxes contribution assumed by the two methods.

c) Systematic appearance of a discontinuity in GPS-TEC time series between the end of the day and the beginning of the next day, especially in presence of disturbances. This is probably due to the lack of observations at the processed local time, since the analysis is a single day analysis (L. Ciraolo, personal communication).

d) The GPS-TEC measurements appear to be smooth in nature in contrary to the highly fluctuated ITEC estimates, especially during day hours. The GPS-TEC estimates are resulted from the conversion of slant TEC to vertical TEC using values from Matera and Ankara averaged in space. In contrary, ITEC estimates are based on the Athens digisonde measurements, which looks directly to the local zenith.
In summary, the comparison shows a reliable behaviour of ITEC variation, which is consistent to the ionospheric storm effects over Athens, as these are described with the GPS-TEC values.

\section{Variation of bottomside/topside electron content during specific storm events}

Several storm events were selected to study the evolution of ionospheric disturbances over Athens.

29 September - 1 October 2000 - During this storm the Dst index reached a minimum value of $-78 \mathrm{nT}$ at $1400 \mathrm{UT}$ on September 30. According to the IMF observations from ACE spacecraft (not shown here) the $Z$ component of the IMF turned southward at the start of the initial phase of the storm. At the same time the solar wind velocity and density remain in their undisturbed values. The weak values of the IMF have as a result a low level of solar wind magnetospheric coupling giving this storm event of moderate intensity that fully recovers on October 2 at 0600 UT.

The $F$ region characteristics, the critical frequency $f_{0} F_{2}$ and the height boundaries of the $F_{2}$ layer $\left(h_{m} F_{2}\right.$ and $h_{m} F_{2}$-B0) are presented in fig. 2, together with the ITEC, BTEC and TTEC estimates over Athens. The solid lines represent the observed parameters. The dotted lines represent the diurnal quiet time behaviour of Athens station formed by the average of the quiet days October $20\left(-2 \mathrm{nT}<D s t<7 \mathrm{nT}\right.$ and $\left.K_{p}<1\right)$ and October $21\left(0 \mathrm{nT}<D s t<18 \mathrm{nT}\right.$ and $\left.K_{p}<2-\right)$, when no substorm activity was detected by the AE indices. Also during the day before, October 19, 2000, only weak isolate substorm activity was recorded by the $A E$ index at auroral latitudes, when -13 $\mathrm{nT}<D s t<3 \mathrm{nT}$ and $K_{p}<3$. The vertical dotted lines mark to local midnight.

During this storm, negative effects were observed during day-time. True height disturbances resulting to the uplifting of the $F_{2}$ layer can be clearly seen, especially during the second night of the storm. ITEC variations in general follow the $f_{0} F_{2}$ disturbances, presenting a noticeable fluctuation during daytime hours. The BTEC and TTEC parameters are following 


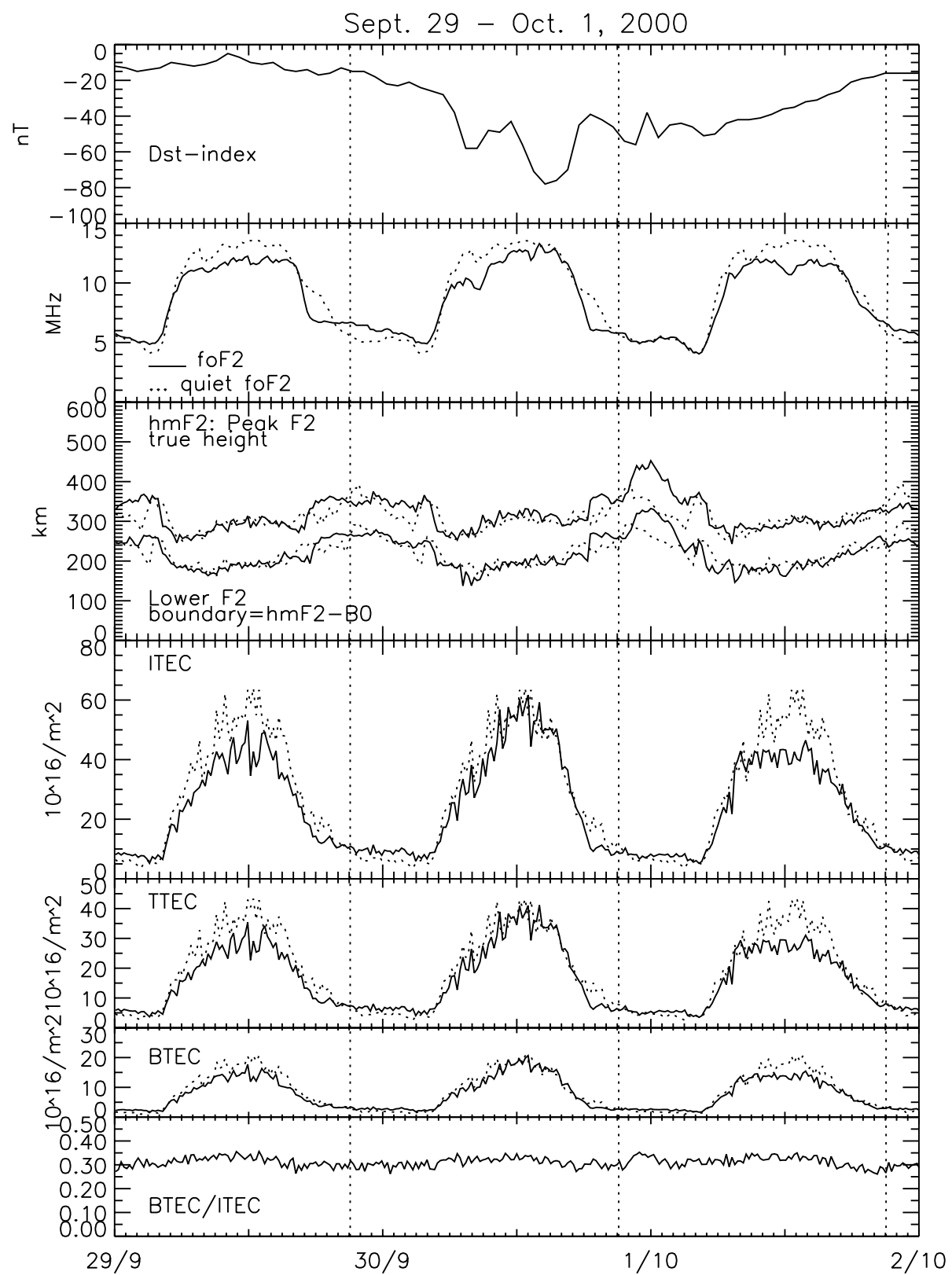

Fig. 2. From the top to the bottom, the $D s t$ index in hourly resolution is presented to have an overall view of the magnetospheric disturbances recorded during the storm occurred between September 29 and October 1, 2000, the $F$ region characteristics, the critical frequency $f_{0} F_{2}$ and the height boundaries of the $F_{2}$ layer $\left(h_{m} F_{2}\right.$ and $h_{m} F_{2}$-B0 $)$ and finally the TEC, BTEC and TTEC estimates over Athens. The solid lines represent the observed parameters. The dotted lines represent the diurnal quiet time behaviour of Athens station. The vertical dotted lines mark to local midnight. 


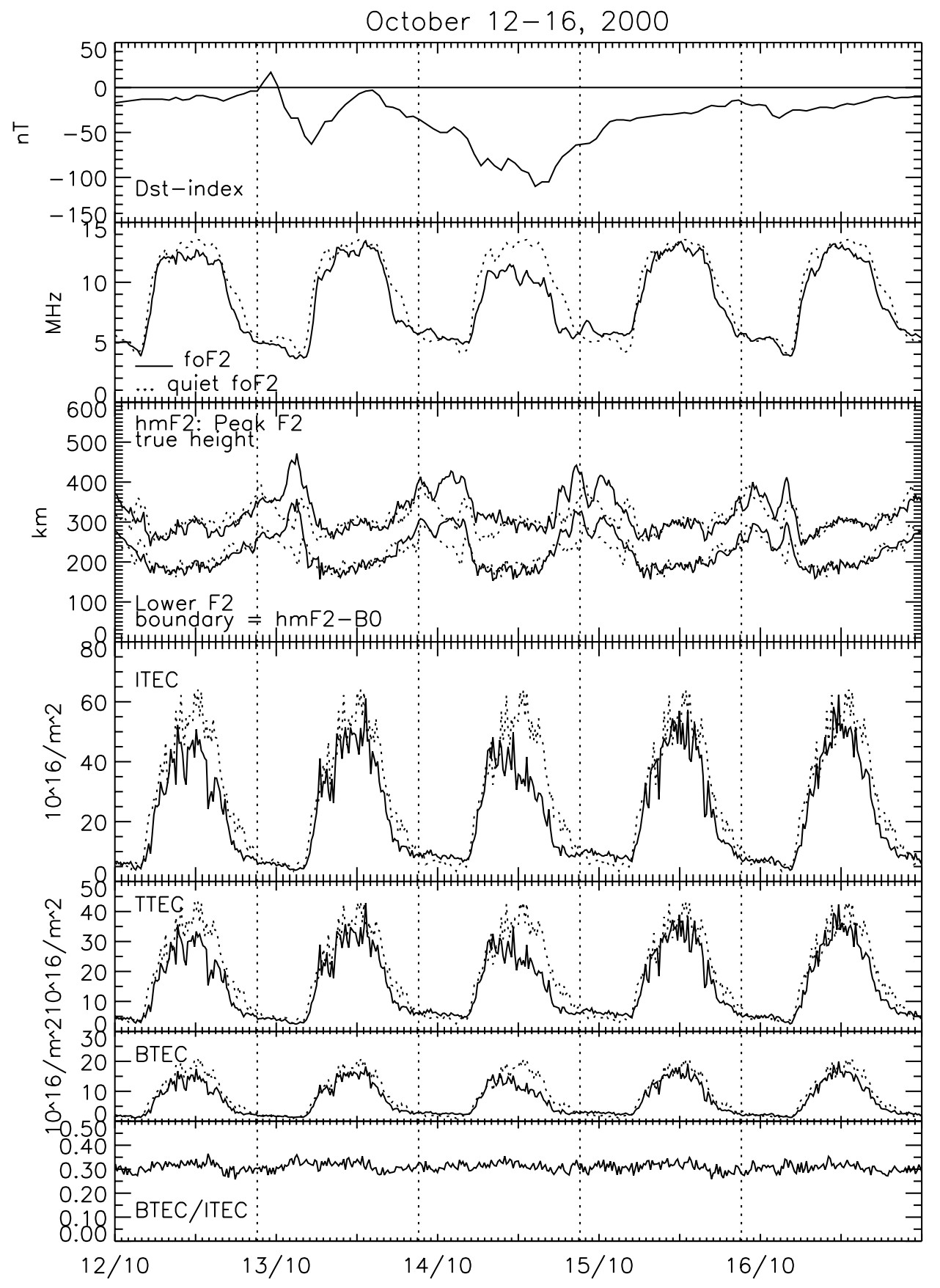

Fig. 3. Same as fig. 2 for the storm interval October 12-16, 2000. 
the ITEC variations. The contribution of the bottomside electron content to the ITEC remains constant throughout the course of this event, as can be seen in the bottom panel of fig. 2 .

12-16 October 2000 - The ionospheric response recorded over Athens during this storm interval is presented in fig. 3 in the same format as in fig. 2 . The diurnal quiet time behaviour of Athens station, overplotted as dotted curve, is formed by the average of the quiet days October 20 and 21. At the beginning of this interval the magnetosphere-ionosphere system was in a moderately disturbed state as it is evident from the negative values of the magnetospheric index Dst, but also from the ionisation depletion observed on October 12, 2000. The start of this storm can be determined as the time of occurrence of a Storm Sudden Commencement (SSC) detected at 2228 UT on October 12. The SSC signify that the earth's magnetic field has been compressed by a shock front from a flare. This results to a rapid ring current development. The Dst index reached a minimum value of $-63 \mathrm{nT}$ at $0500 \mathrm{UT}$ on October 13 . The storm recovery phase lasted $9 \mathrm{~h}$. Immediately afterwards the Dst index started to decrease again, with a slow rate this time indicating that the large-scale magnetospheric convection caused a slow development of the ring current that gave the second storm observed during this period with the $D s t$ index reaching its minimum value of $-110 \mathrm{nT}$ at 1600 UT on October 14.

The main observations regarding the $F_{2}$ layer response may be summarized as follows:

- Negative effects are observed at night from 12 to 13 October over Athens. This is the ionospheric response to the first storm event caused by an SSC. The bottomside, topside and total electron content shows also a negative response, following the $f_{0} F_{2}$ variations. During the second night of this time interval (13 to 14 October), that corresponds to the initial and main phase of the second storm, positive nighttime effects were seen in Athens. The same pattern was observed during the next two nights (14 to 15 and 15 to 16 October) during which the magnetic storm was in its recovery phase. The electron content in the bottomside and topside ionosphere increases also in respect to their quiet values. The contribution of BTEC to the total electron content remains constantly equal to approximately the $1 / 3$ as can be seen in the bottom panel of fig. 3 .

- A noticeable up lifting of the $F_{2}$ layer is observed at night. The estimated $h_{m} F_{2}$ parameter is smoother in nature during these night-time uplifting events rather during daylight, where the height boundaries of the $F_{2}$ layer remain in their undisturbed values. This is reflected in the ITEC values also. These daytime fluctuations in ITEC, if really exist, are of great importance for navigation and positioning systems.

2-8 October 2000 - The second storm is more intense and its development consists of two distinct steps. The start of the $D s t$ decrease $(\sim 0700$ UT on October 2$)$ coincides with a weak southward turning of the IMF, according to ACE data (not shown here). A SSC, occurred at 0054 UT on October 3, marks the start of the main phase of the storm development. This storm seems to recover with the Dst reaching a minimum of $-23 \mathrm{nT}$ at $0200 \mathrm{UT}$ on October 4. Right afterwards, Dst index starts to decrease again with a high rate of change, marking the initial phase of the second step of this storm. A well-defined SSC event occurred at 0326 UT on October 5 caused new storm intensification and a reactivation of the main phase of the storm, with the Dst index reaching its maximum of $-192 \mathrm{nT}$ at $1400 \mathrm{UT}$ on October 5. This was also the start of the recovery phase of the storm. This storm can be classified as a Type B storm (Kamide et al., 1998) as the ring current presents a two-step development. This is initially the result of large-scale convection in the magnetosphere, and eventually substorm associated injection of ionospheric oxygen ions into the inner magnetosphere.

The time variation of the $F_{2}$ layer parameters is presented in fig. 4 in the same format as fig. 2. The diurnal variation of the quiet time is formed by the average of the quiet days October 20 and October 21. The variations of the $f_{0} F_{2}$ critical frequency parameter are well correlated to the ITEC variations and the BTEC and TTEC parameters are following. During day-time the ITEC over Athens increases or decreases fol- 


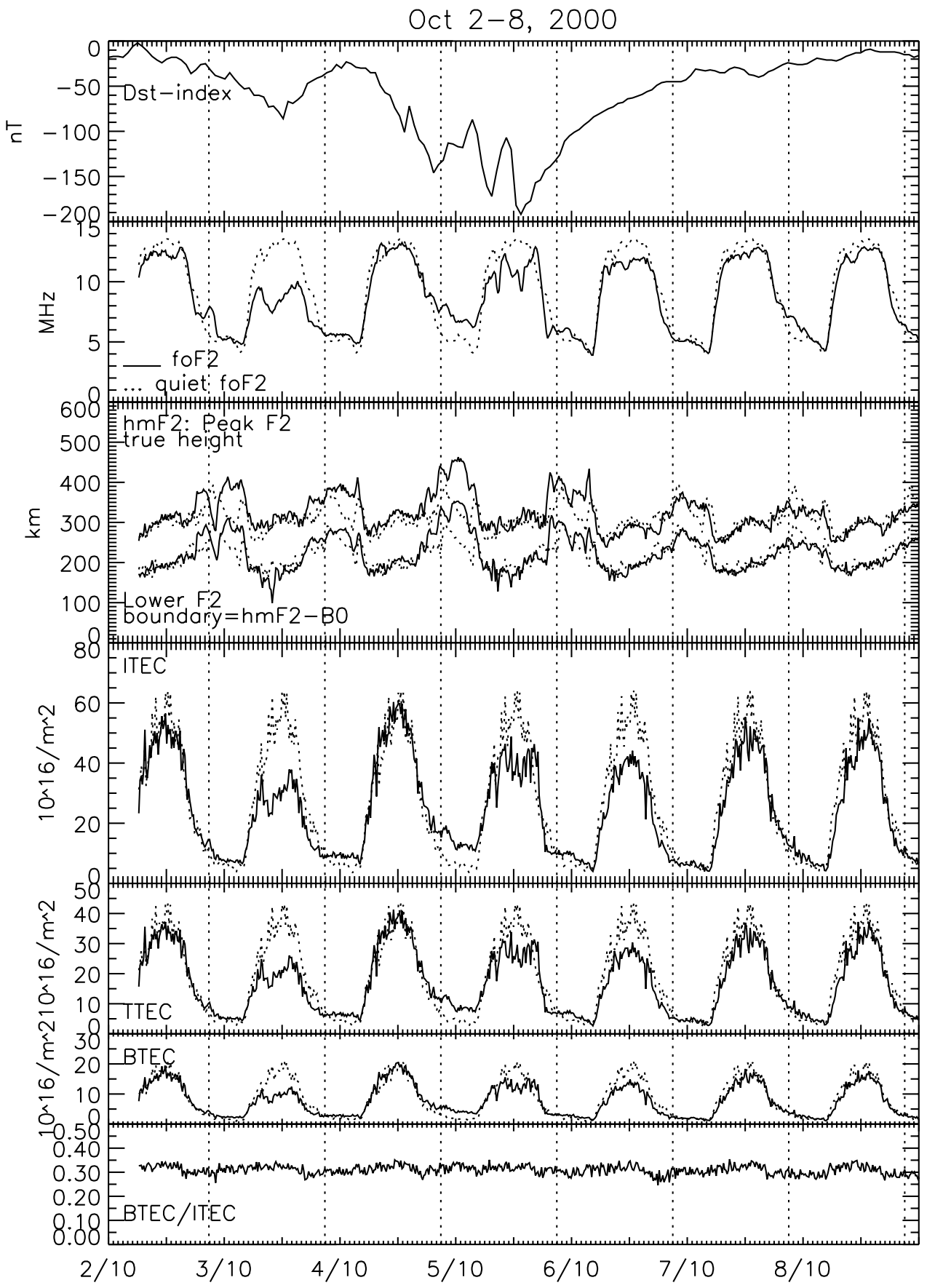

Fig. 4. Same as fig. 2 for the storm interval October 2-8, 2000. 


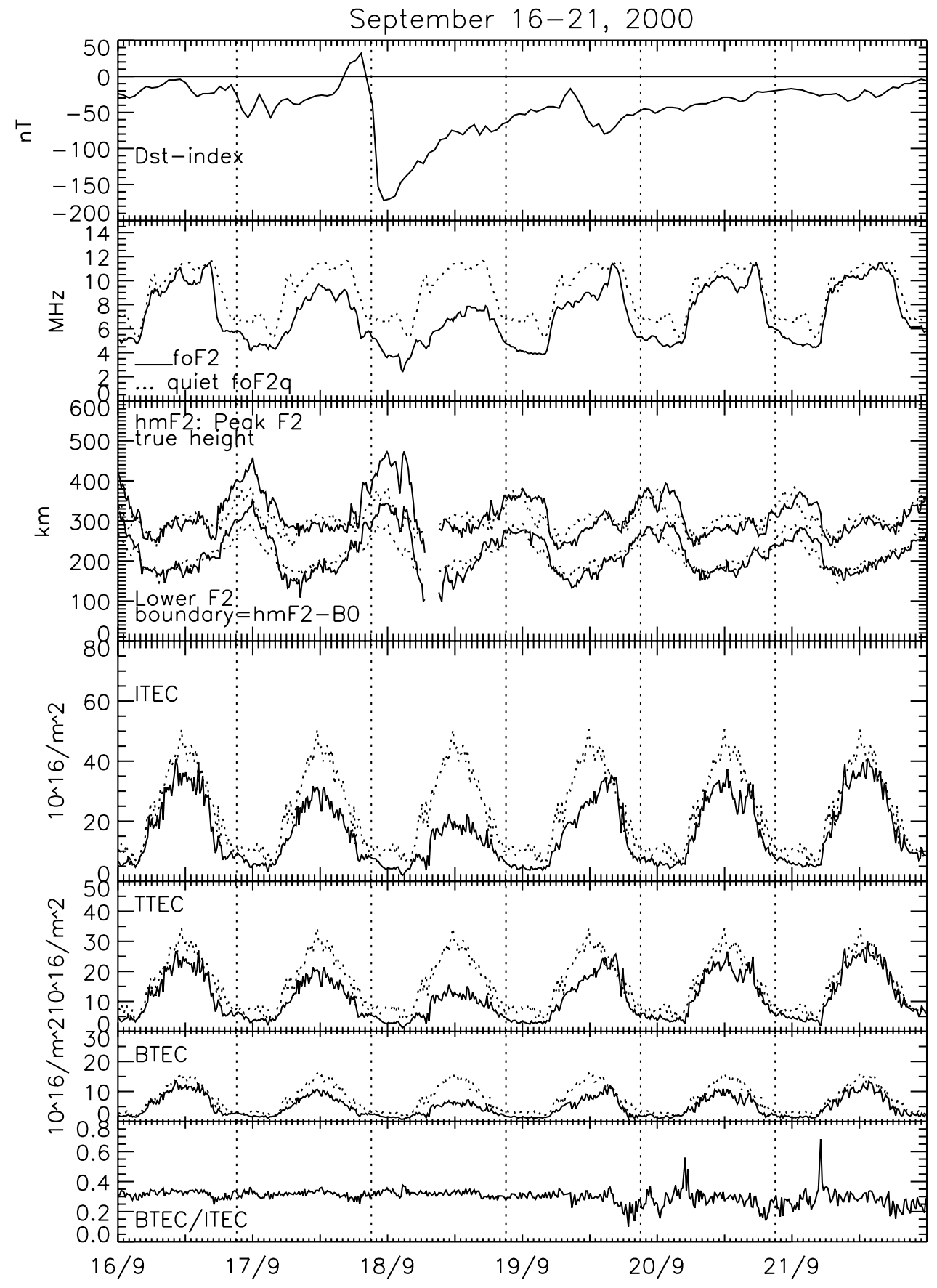

Fig. 5. Same as fig. 2 for the storm interval September 16-21, 2000. 
lowing the positive and negative storm phases, respectively. During night-time, ionisation enhancements recorded over Athens (e.g., the nights between 2-3 and 4-5 October) are coincided with ITEC enhancements.

The uplifting of the $F_{2}$ layer that was detected during the first four nights of the storm development, caused probably to waves launched from the auroral oval at each substorm activation, are correlated neither to ionisation variations extracted by $f_{0} F_{2}$, nor to ITEC variations. It is also noticeable that during night-time uplifting events of the $F_{2}$ layer, the electron content appears again to be smoother in nature compared to other intervals where no height variations are observed in $F_{2}$ layer for instance during the last two days of this storm interval.

16-21 September 2000 - An Interplanetary Coronal Mass Ejection (ICME) occurred during this interval caused a gradual increase of the solar wind velocity whose values reached the $850 \mathrm{~km} / \mathrm{s}$ and large increase in solar wind density (from ACE data, not presented here). The Dst index was already depressed prior to the arrival of the shock, caused by two Storm Sudden Commencements (SSC) occurred at 0450 UT and 1912 UT on September 15, 2000, according to NOAA archives (http://www.ngdc.noaa.gov/ stp/GEOMAG/geomag1.html). A fast forward shock arrives at 1900 UT on September 17 causing rapid decrease in the $D$ st index, reaching its minimum value equal to $-172 \mathrm{nT}$ at 2300 UT on September 17. While the system recovered, at 1444 UT on September 18 a new SSC caused a deceleration in $D s t$ recovery. This time Dst reached the minimum value of $-80 \mathrm{nT}$ on September 19, which recovered slowly until the end of the next day.

The behaviour of the ionosphere over Athens is presented in fig. 5, showing the time plots of the critical $f_{0} F_{2}$ frequency and of the height boundaries of the $F_{2}$ layer together with the $D s t$ index. The variation of ITEC, TTEC and BTEC parameters is presented at the bottom of fig. 5 . The dotted lines represent the diurnal quiet time behaviour formed by the corresponding observations during the quiet day September 11 $\left(9 \mathrm{nT}<D s t<24 \mathrm{nT}\right.$ and $\left.K_{p}<1\right)$, when no substorm activity was detected by the AE indices. Also during the day before, September 10,2000 , no substorm activity was recorded by the $A E$ index at auroral latitudes, when $0 \mathrm{nT}<$ $D s t<20 \mathrm{nT}$ and $K_{p}<1$.

Night-time ionisation depletion was observed over Athens during this disturbed interval, which is deduced from $f_{0} F_{2}$ and BTEC and TTEC time variations. Noticeable uplifting of the $F_{2}$ layer is observed during the first two nights of this interval (16 to 17 and 17 to 18 September) with the maximum increase in height observed the second night of the major storm occurrence. Large amplitude fluctuations are observed in electron content estimates during daytime whereas during nighttime $F_{2}$ layer uplifting events these values are smoother in nature. All quantities BTEC, TTEC and ITEC present the same behaviour and correlate perfectly with $f_{0} F_{2}$ variations. The relative contribution of BTEC to the ITEC remains constantly equal to $\sim 0.3$.

Table I. The main characteristics of the five geomagnetic storms analysed in this paper.

\begin{tabular}{|c|c|c|c|c|}
\hline Storm event & Dst-min & $\partial D s t / \partial t$ & $\begin{array}{c}\text { Standard deviation } \\
\Delta \text { TTEC } \%-\Delta \text { ITEC } \%\end{array}$ & $\begin{array}{c}\text { Standard deviation } \\
\Delta \mathrm{BTEC} \%-\Delta \mathrm{ITEC} \%\end{array}$ \\
\hline 29 Sept.-1 Oct. 2000 & $-78 \mathrm{nT}$ & $2.8 \mathrm{nT} / \mathrm{h}$ & 3.4 & 8.5 \\
\hline $12-13$ Oct. 2000 & $-63 n T$ & $5.3 \mathrm{nT} / \mathrm{h}$ & 3.5 & 8.5 \\
\hline 13-16 Oct. 2000 & $-110 \mathrm{nT}$ & $4.1 \mathrm{nT} / \mathrm{h}$ & 3.8 & 9.5 \\
\hline 2-8 Oct. 2000 & $-192 \mathrm{nT}$ & $\begin{array}{l}\text { 1st step: } 2.9 \mathrm{nT} / \mathrm{h} \\
\text { 2nd step: } 4.8 \mathrm{nT} / \mathrm{h}\end{array}$ & 4.1 & 10.4 \\
\hline 16-21 Sept. 2000 & $-175 \mathrm{nT}$ & $51 \mathrm{nT} / \mathrm{h} 11.1 \mathrm{nT} / \mathrm{h}$ & 4.9 & 11.1 \\
\hline
\end{tabular}




\section{Statistical analysis of observations}

In accordance with the above analysis, five geomagnetic storms were determined during the selected time intervals. Their characteristics are summarized in table I. Their intensity is expressed in terms of the minimum Dst value at the end of the main phase and also in terms of the Dst decrease rate. To distinguish between the behaviour of bottomside and topside electron content during storm intervals, we estimated the standard deviation of the relative disturbance of TTEC and BTEC in respect to their quiet values ( $\triangle \mathrm{TTEC} \%$ and $\triangle \mathrm{BTEC} \%$ respectively), from the corresponding ITEC relative deviations $(\triangle \mathrm{ITEC} \%)$, for each storm separately. The results are plotted in fig. 6a-e and the numerical values are presented in the last two columns of table I. There are two groups of events: The first three
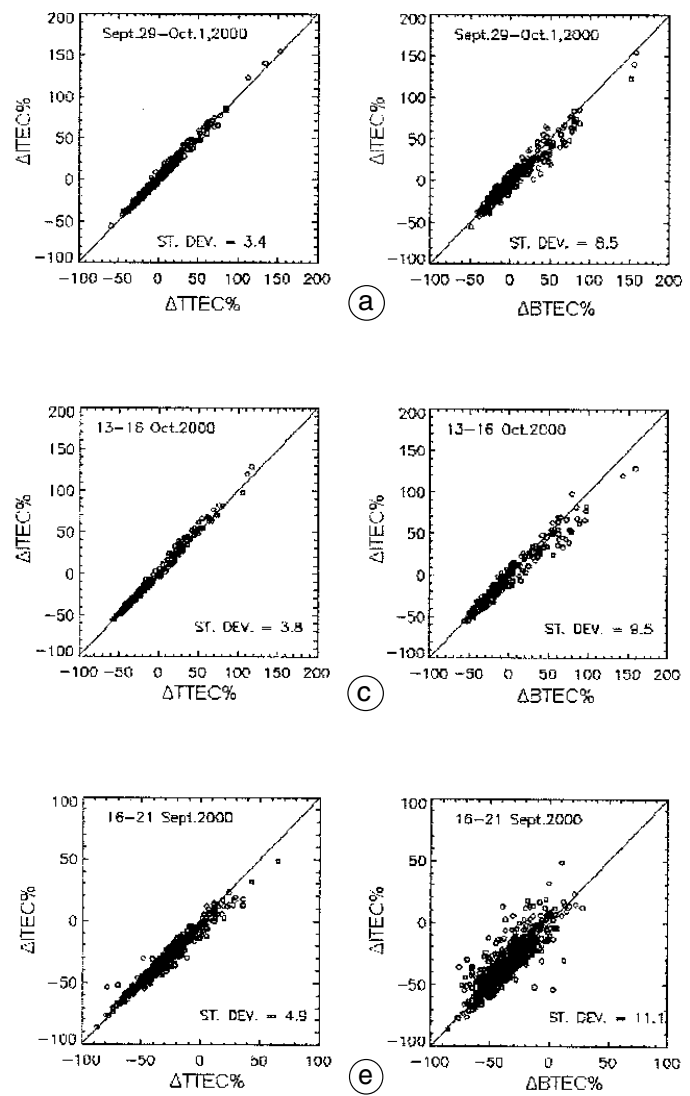

storms are of rather moderate intensity, according to the minimum $D s t$ value; the last two are intense storms. It is concluded that as geomagnetic activity increases, the TTEC is more drastically perturbed rather than BTEC. It follows that TTEC is more sensitive to geomagnetic activity.

As a next step, we studied the variations of the time derivative of TTEC and BTEC in absolute values, with the $h_{m} F_{2}$ time derivative. The results are presented in fig. 7a-e for the five storm intervals separately.

It is obvious that the topside electron content varies much more drastically with the variations of the true height of the $F_{2}$ layer, giving one more evidence that TTEC is more sensitive to geomagnetic activity, since height variations are mostly caused by geomagnetic disturbances, at least for the time intervals considered in this study.
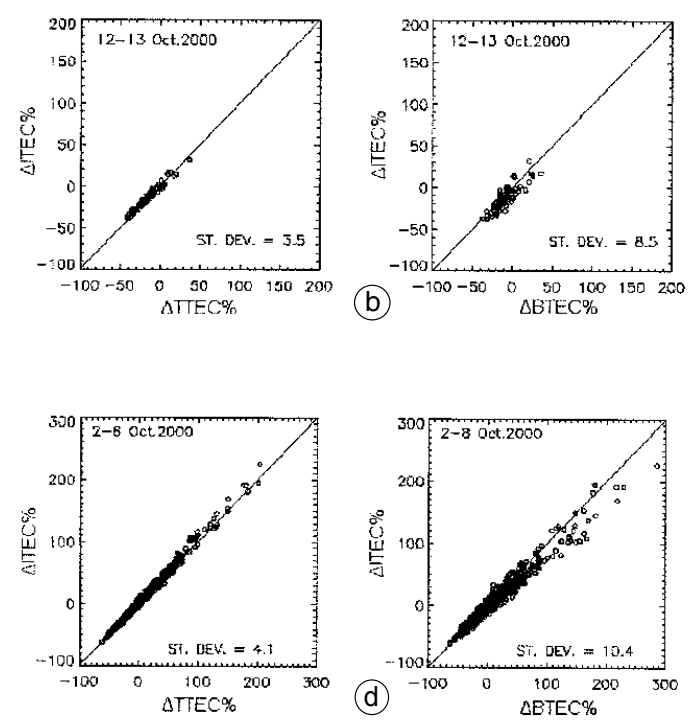

Fig. 6a-e. The standard deviation of the relative disturbance of TTEC and BTEC in respect to their quiet values ( $\triangle \mathrm{TTEC} \%$ and $\triangle \mathrm{BTEC} \%$ respectively), from the corresponding ITEC relative deviations ( $\triangle \mathrm{ITEC} \%)$, for each storm separately. 

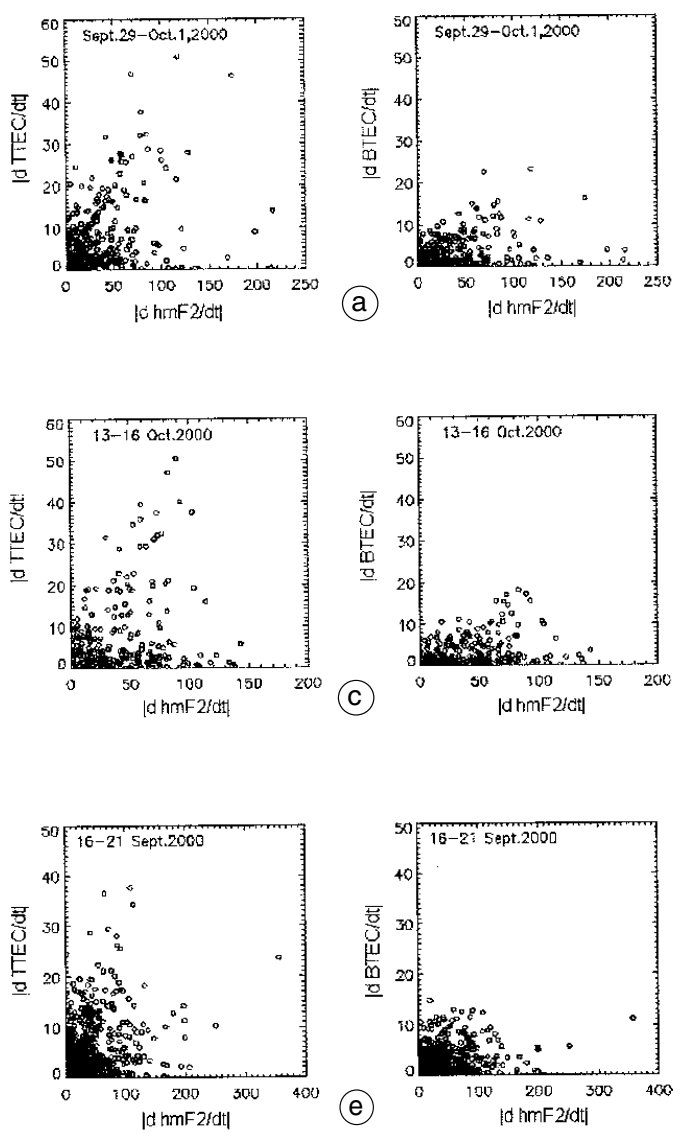

\section{Discussion and conclusions}

In this work we analyzed ionospheric observations from Athens Digisonde (the $f_{0} F_{2}$ critical frequency), and also various estimates that determine the structure of the ionosphere over Athens such as: the true height of the peak of the $F_{2}$ layer, $h_{m} F_{2}$, extracted by the true height bottomside electron density profile according to the Huang and Reinisch (1996) inversion technique; the bottomside electron content (BTEC) estimated as the integral of the electron concentration up to the peak height of the $F_{2}$ layer; the topside electron content (TTEC) according to the newly proposed technique of Huang and Reinisch (2001), estimated as the integral of the topside electron density profile up to the $1000 \mathrm{~km}$; the total electron content
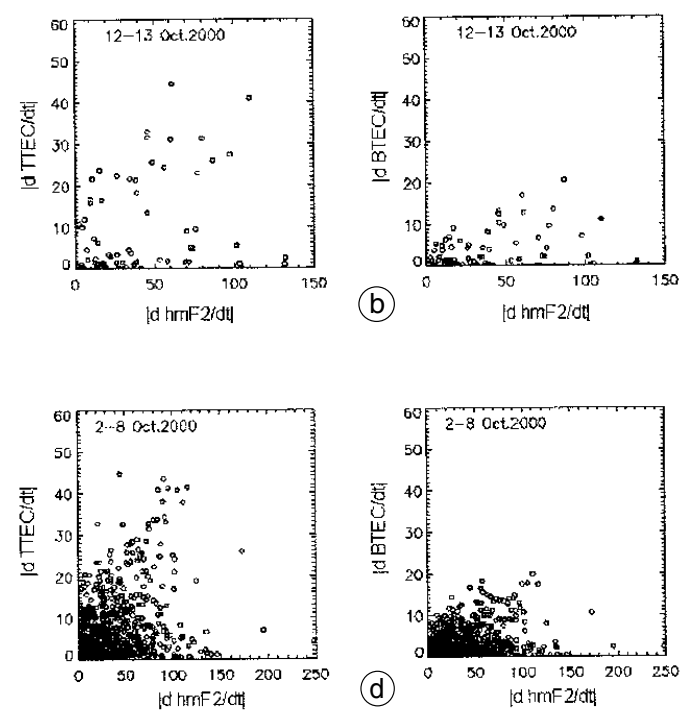

Fig. 7a-e. The variations of the time derivative of TTEC and BTEC in absolute values, with the $h_{m} F_{2}$ time derivative for the three storm intervals separately.

(ITEC) estimated as the sum of the bottomside and topside electron content. It should be noted that BTEC and TTEC estimates are two independent parameters, since two different techniques are followed for their derivation.

The aim of this paper was to investigate the behaviour of the two parameters BTEC and TTEC during storm events. To approach this goal, first we presented a comparison between the ITEC estimates over Athens, and the TEC estimates from the ground GPS network provided by L. Ciraolo (fig. 1). The two curves have a surprising good agreement during either quiet or disturbed periods. Nevertheless both methods (the Huang and Reinisch, 2001 method for ITEC estimation from ground ionograms only, and the well known technique of TEC estimation from ground GPS networks) have 
some limitations. To obtain the optimum results using the Huang and Reinisch method, especially at times of ionospheric disturbances, the automatic ionogram scaling results should be checked for their correctness because faulty echo traces will produce wrong ITEC values. On the other hand, the method of deriving TEC from GPS measurements introduces significant errors during night-hours, which have to be taken under consideration.

The next step of this investigation was to analyze the variation of TTEC and BTEC parameters during storm events of different intensity. The first and the second storm (29 September - 1 October and 12-13 October 2000) were of moderate intensity. The third one (13-16 October 2000) was a rather intense storm and the last two storms were very intense events (2-8 October and 16-21 September 2000). Two of these storms were characterized by the occurrence of a SSC at the beginning of the initial phase (12-13 October 2000, 16-21 September 2000). The other three storms were the result of the large-scale convection system of the magnetosphere, and are characterized as «gradual driven» storms. The two different types of storms caused different ionospheric effects over Athens (Belehaki and Tsagouri, 2002). The storms with SSC produced negative effects while the gradual driven storms caused ionisation depletion during the day and ionisation enhancements during the night, according to the $f_{0} F_{2}$ variations. The ITEC variations are in very good correlation with the $f_{0} F_{2}$ variations in both types of storms.

The main characteristics of the topside electron content calculated according to the Huang and Reinisch (2001) method, as raised from this analysis, may be summarized as follows: The topside electron content represents roughly the $2 / 3$ of the total electron content of the ionosphere and it is strongly affected by the geomagnetic activity, much more than the bottomside electron content as it is extracted from the analysis presented in fig. 6a-e. During daylight hours the TTEC values exhibit intense fluctuations. TTEC becomes smoother in nature during events of night-time $F_{2}$ layer uplifting caused by the auroral activity.

All these facts demonstrate that the ITEC proved to be a realistic tool for monitoring the variations of ionospheric ionisation. Indeed, the variations of TTEC and BTEC parameters reflect the effects of ionospheric disturbances at a given location. The great importance of the Huang and Reinisch (2001) method for a more comprehensive discussion of ionospheric storm phenomena, in particular if simultaneously measured GPS derived TEC data are available, is the most important conclusion of this study. The cooperation of as many as possible ground ionosondes having the capability to compute the ITEC parameter in association with the GPS-TEC measurements could lead to the development of realistic models for the accurate prediction of electron content during either disturbed or undisturbed intervals, to support effectively earth-space communications including navigation systems.

\section{Acknowledgements}

We thank Luigi Ciraolo, Istituto di Ricerca sulle Onde Elettromagnetiche in Florence, Italy, for providing us with the GPS-TEC values and for the constructive comments; and Bruno Zolesi, Istituto Nazionale di Geofisica e Vulcanologia, for helpful discussions and useful suggestions.

\section{REFERENCES}

BELEHAKI, A. and I. TSAGOURI (2002): On the occurrence of storm induced nighttime ionization enhancements at ionospheric middle latitudes, J. Geophys. Res. (in press).

Ciraolo, L. and P. Spalla (1997): Comparison of ionospheric total electron content from the navy Navigation Satellite System and the GPS, Radio Sci., 32 (3), 1071-1080.

Ho, M.C., A.J. MANNUCCI, U.J. Lindowister, X. PI and T.T. TSURUTANI (1996): Global ionosphere perturbations monitored by the worldwide GPS network, Geophys. Res. Lett., 23, 3219-3222.

HuANG, X. and B.W. REINISCH (1996): Vertical electron density profiles from the Digisonde network, $A d v$. Space Res., 18 (6), 121-129.

HuANG, X. and B.W. ReINISCH (2001): Vertical total electron content from ionograms in real time, Radio Sci. (Special Issue for IES Meeting), 36 (2), 335-342.

JAKOWSKI, N., E. PUTZ and P. SPALLA (1990): Ionospheric storm characteristics deduced from satellite radio beacon observations at three European stations, Ann. Geophys., 8, 343-352. 
JAKOWSKI, N., S. SCHLUTER and E. SARDON (1999): Total electron content of the ionosphere during the geomagnetic storm on 10 January 1997, J. Atmos. SolarTerr. Phys., 61, 299-307.

KAMIDE, Y., N. YOKOYAMA, W. GONZALEZ, B.T. TSURUTANI, I.A. DAGLIS, A. BREKKE and S. MASUdA (1998): Twostep development of geomagnetic storms, J. Geophys. Res., 103, 6917.

REINISCH, B.W. and X. HUANG (1983): Automatic calculation of electron profiles from digital ionograms, 3 , processing of bottomside ionograms, Radio Sci., 18, 477.

REINISCH, B.W., X. HUANG, A. BELEHAKI and J.-C. JODOGNE (2001): Bottom and topside ionospheric TEC obtained from ground-based ionosonde measurements, in Proceedings of the International Beacon Satellite Symposium, Boston College, MA.

Titheridge, J.E. and M.J. Buonsanto (1980): A comparison of northern and southern hemisphere TEC storm behaviour, J. Atmos. Terr. Phys., 50, 763-780. 